\title{
Unbalanced Variable Nonlinear Load Compensation Using Multiple Shunt Active Filters
}

\author{
Deepthi Janyavula*, Dr. Satyendra Nath Saxena** \\ * Department of Electrical Engineering, Government Polytechnic Sangareddy, Telangana, India \\ ** EEE Department, Gokaraju Rangaraju Institute of Engineering \& Technology, Hyderabad, Telangana, India
}

\begin{abstract}
Article Info
Article history:

Received May 7, 2015

Revised Aug 10, 2015

Accepted Aug 26, 2015

\section{Keyword:}

Pulse-width-modulation Shunt active filter Total harmonic distortion Unity power factor Zero voltage regulation

ABSTRACT

The proposed scheme has considered a three-phase four-wire system, which experienced sag and swell in source voltage for a certain period while feeding an unbalanced and variable non-linear load. The load has unequal resistive and reactive elements in the three phases, forming the unbalanced component. A three-phase silicon controlled rectifier converter with adjustable firing angle connected to the load has formed the variable nonlinear component. This has been considered, so as to simulate the unbalanced and variable non-linear nature of loads in real-time power system. The trends in the total harmonic distortion variation were obtained for the proposed system under power factor correction and voltage regulation mode operation when the load-side converter firing angles of $30^{\circ}, 60^{\circ}$ and $90^{\circ}$ were considered using MATLAB/SIMULINK software. Three pulse-widthmodulation methods, namely, sinusoidal pulse-width-modulation, space vector modulation and hysteresis pulse-width-modulation have been used to generate pulses for the voltage source converter of the shunt active filter based on the reference currents generated using synchronous reference frame theory. It has been demonstrated in the proposed paper that power factor correction, voltage regulation, better harmonic reduction and hence load compensation are obtained simultaneously by using two SAFs.
\end{abstract}

Copyright @ 2015 Institute of Advanced Engineering and Science. All rights reserved.

\section{Corresponding Author:}

Deepthi Janyavula, Department of Electrical \& Electronics Engineering, Government Polytechnic, Sangareddy, Telangana, India 502001

Email: deepthi.billla@gmail.com

\section{INTRODUCTION}

Power systems are becoming highly unpredictable due to the rapidly changing nature of the loads. Unbalanced and nonlinear loads are widely prevalent in modern day power systems. Unbalanced load occur mainly due to connection of large single phase loads, phase-to-phase loads and connection of different values of loads in each phase. This will yield excessive neutral current and heating. In the presence of non-linear load, the current waveform gets deformed, which produces harmonics. This has become a matter of concern for the power utilities due to the expeditious growth of non-linear loads in industrial and domestic applications.

A detailed study of THD variation with respect to several industrial and domestic appliances has been presented in [1], [2]. In these papers, a comprehensive explanation has been given about harmonics and their causes and effects on power systems due to the presence of different types of non-linear loads. A harmonics power flow code for estimating harmonics was experimented on various non-linear loads for IEEE 6-bus and 14-bus systems in [3]; in which, the influence of harmonics on electrical networks has been established for various conditions of operation. A current-controlled voltage source converter (VSC)-based shunt active filter (SAF) has been proposed in [4]. In this paper, a combination of unbalanced and non-linear 
load is connected to a three-phase four-wire distribution system; and the operation of SAF has been demonstrated under voltage regulation and power factor correction modes of functioning. But, concurrent voltage regulation and power factor correction has not been explained in the prior art. The proposed paper has demonstrated the concurrent power factor correction and voltage regulation along with harmonic reduction using multiple SAFs; where, one SAF operates in power factor correction mode, and the other SAF operates in voltage regulation mode. Section 2 explains about SAF and its prior art. Section 3 exhibits the proposed system configuration. Section 4 gives the results obtained under various conditions of operation considered. Section 5 concludes the paper by collating the results.

\section{SHUNT ACTIVE FILTER}

Passive filters used for power quality improvement have several disadvantages, such as, source loading, bulky circuit, fixed compensation and lack of isolation between input and output. To overcome these drawbacks, passive filters are being replaced by active filters, which overcome most of the drawbacks of passive filters. The results obtained by connecting passive and active filters in order to reduce the active power filter rating were presented in [5], [6]. Several authors have explained the significance of SAF in improving the quality of power in power systems applications. A critique of existing approaches, classification and assessment of active power filters for power quality improvement was given in [7], [8]. Trends in power conditioning using active filters were given in [9]; where, detailed analysis of different types of SAFs, their configurations, component selection and control strategies was elucidated. Various strategies for extracting the reference currents of SAF were compared in [10]. A novel control strategy for SAF with minimum current measurement was detailed in [11], which explained about the source and load current detection methods. In the proposed work, load current detection method has been used.

The basic configuration of the single SAF connected to the point of common coupling (PCC) is presented in Figure 1. The proposed SAF is a VSC, connected in parallel to the system to be compensated at the PCC using an inductive interface, such as, a transformer, which isolates the SAF from the remaining part of the system. The SAF can be employed to perform tasks, such as, load balancing, power factor correction, voltage regulation and harmonic reduction. Unbalanced load means that all the three phases are not equally loaded, which will increase the neutral current significantly. SAF will balance the effect of unbalanced load and reduce the neutral current in supply to zero. Presence of non-linear elements in the load will cause deviation of the power factor from unity and introduce harmonics into the system. The SAF will reduce the harmonics to the acceptable limit and ensure the unity power factor operation. SAF can also aid the system in maintaining zero voltage regulation in order to reduce voltage flicker, sag and swell. The usage of custom power devices for reducing voltage flicker, sag and swell has been demonstrated in [12], [13]; but, the aspect of power factor correction has not been considered while improving the power quality. Unity power factor operation of SAF is explained and indicated as appropriate when the source voltage has distortions in [14]; but, the aspect of voltage regulation was not looked into. Hence, it has to be noted that, using a single SAF, power factor correction and voltage regulation cannot be obtained simultaneously.

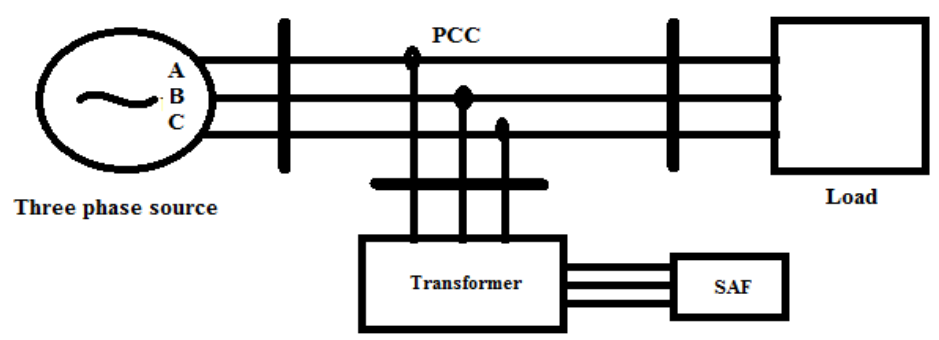

Figure 1. Basic configuration of a shunt active filter

\section{PROPOSED SYSTEM}

The proposed system is a three-phase four-wire system, consisting of a three-phase AC source connected to a load, which comprises of unbalanced and non-linear components. The source voltage experiences sag and swell of $25 \%$ during the intervals $(0.2-0.3) \mathrm{s}$ and $(0.6-0.8)$ s, respectively. The load is made up of a combination of unbalanced and variable non-linear elements. Resistive and inductive components of unequal values are connected in the three-phases, which will introduce unbalance in the load. 
The non-linear load is made up of a three-phase silicon controlled rectifier (SCR) converter, whose firing angle can be modified in order to vary the non-linearity. First, a single SAF is connected at the PCC by using a three-phase two-winding star-delta transformer. A three-phase R-C filter is also connected at the PCC, which aids in bringing down the voltage harmonics. The parameters of the scheme considered are presented in Table 1.

Table 1. Proposed system parameters

\begin{tabular}{lrl}
\hline Parameter & \multicolumn{1}{l}{ Value } \\
\hline \multicolumn{2}{l}{ Source RMS voltage : } & $415 \mathrm{~V}$ \\
System frequency $\quad:$ & $50 \mathrm{~Hz}$ \\
Line impedance $\quad:$ & $(0.01+\mathrm{j} 0.626) \Omega$ \\
Ripple filter & $:$ & $\mathrm{R}_{\mathrm{f}}=5 \Omega, \mathrm{C}_{\mathrm{f}}=5 \mu \mathrm{F}$ \\
& & R Phase: $25 \Omega, 1 \mathrm{mH}$ \\
Unbalanced load $\quad:$ & Y Phase: $5 \Omega$ \\
& & B Phase: $10 \Omega, 5 \mathrm{mH}$ \\
Nonlinear load $\quad:$ & Three-phase $\mathrm{SCR}$ converter with $\mathrm{R}=25 \Omega$ \\
DC bus voltage & $:$ & $700 \mathrm{~V}$ \\
DC bus capacitance : & $3 \mathrm{mF}$ \\
\hline
\end{tabular}

The MATLAB/SIMULINK model of the proposed system with a single SAF connected at the PCC is shown in Figure 2. An insulated gate bipolar transistor (IGBT)-based VSC is connected as SAF in the proposed system in order to accomplish the load compensation. The operation of SAF depends on two aspects; first one is the control algorithm of the SAF; and the second one is the pulse-width-modulation method used to generate the pulses for the IGBTs of VSC.

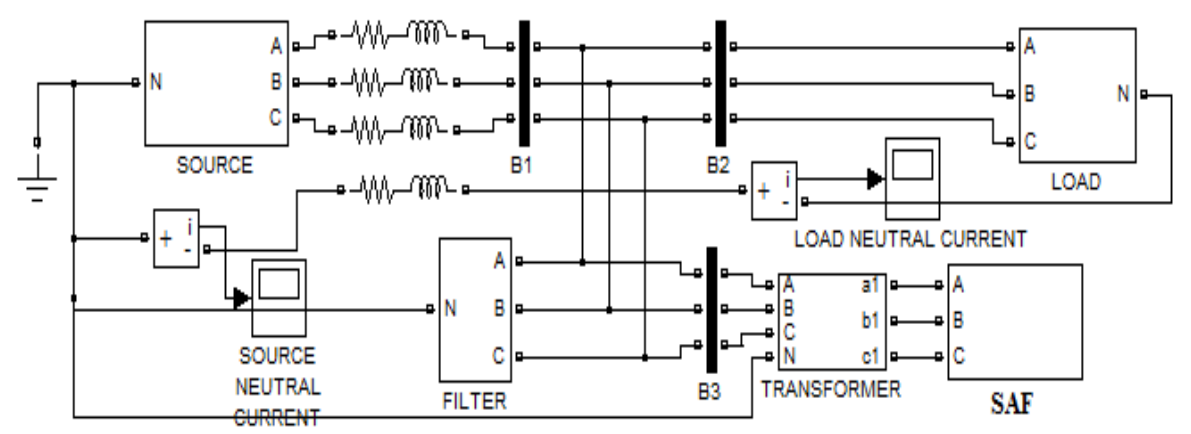

Figure 2. Single SAF connected to three-phase four-wire system

Several control techniques, such as, decoupled current theory, Adaline based algorithm, constant source instantaneous power strategy, sinusoidal source current strategy and synchronous reference frame theory were reported in [15], [16]. In the present work, synchronous reference frame theory based algorithm is utilized to control the SAF. Techniques such as genetic algorithm based and Zigler-Nichols methods have been reported in literature [17], [18] in order to tune the PI controller of the control algorithm. Simple trial and error method has been applied in the proposed work to tune the PI controller gains. Several transformer configurations for connecting the SAF to the power system were also investigated [19]. In the proposed work, a star-delta transformer is used to connect a single SAF to the proposed system at the PCC.

Holtz presented a detailed survey of pulse-width-modulation techniques in [20]. In the proposed work, sinusoidal pulse-width-modulation (SPWM), space vector modulation (SVM), and hysteresis pulsewidth-modulation (HPWM) have been utilized to generate the pulses to the VSC of SAF.

The single SAF can be operated either in UPF mode or ZVR mode. Moreover, source neutral current compensation, harmonic elimination and load balancing can also be obtained by using SAF. Due to the non-linear nature of the load, the voltage and source current will not be in phase. When the SAF operates in UPF mode, source current can be made to be in phase with the voltage. Since the source voltage has sag and swell, in ZVR mode, the load voltage can be regulated. But, the simultaneous operation of UPF and ZVR modes cannot be accomplished by using a single SAF. To overcome this drawback, two SAFs are connected 
to the same system under consideration using a three-phase three-winding star-delta-delta transformer, as depicted in Figure 3.

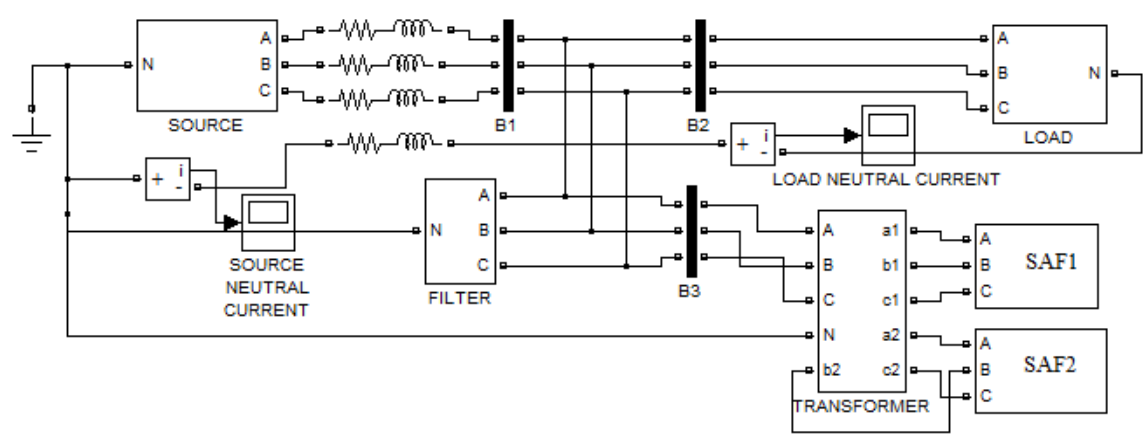

Figure 3. Two SAFs connected to three-phase four-wire system

The next section explains the results obtained when one/two SAFs operating in UPF/ZVR mode employing SPWM/SVM/HPWM are applied in order to compensate an unbalanced variable non-linear load connected to the proposed three-phase four-wire arrangement.

\section{RESULTS AND DISCUSSION}

For the system under consideration without SAF, source neutral current is as shown in Figure 4. The source voltage, source current, load voltage, and load current without SAF are given in Figure 5. It can clearly be seen from Figure 4 that the source neutral current is not zero since the load is unbalanced, which results in an undesirable source neutral current. Moreover, Figure 5 indicates that there is a sag and swell in the source voltage as elucidated in the previous section. All the waveforms correspond to the results obtained when the firing angle of SCR converter connected to the load is $30^{\circ}$ and SPWM is used to generate pulses to the VSC of the SAF.

Figure 6 shows that the source neutral current became zero with SAF. The load is unbalanced, but still the source neutral current is observed to be zero during the entire period. Figure 7 and Figure 8 depict the waveforms when one SAF is used for compensation and is controlled by SPWM in UPF mode of functioning. Figure 7 shows that the PCC voltage and source current are in phase with respect to each other. Figure 8 shows the source, PCC and load voltages in UPF mode of operation. Moreover, it can be determined from Figure 8 that the load voltage is not regulated, i.e., ZVR mode of operation cannot be obtained by SAF in the UPF mode of functioning.

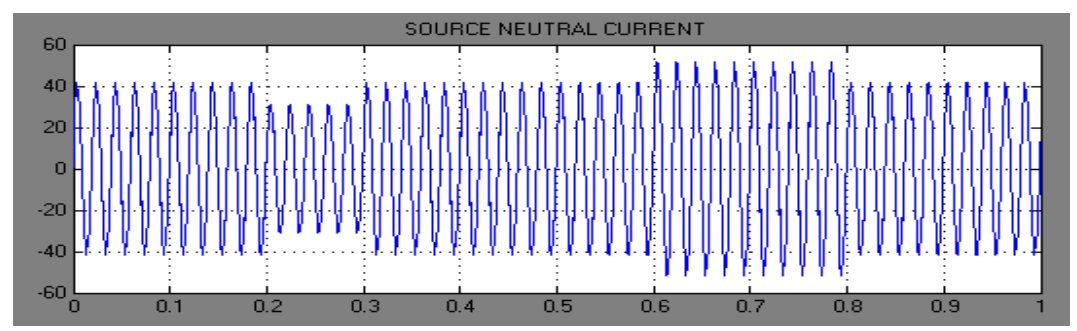

Figure 4. Source neutral current without SAF 


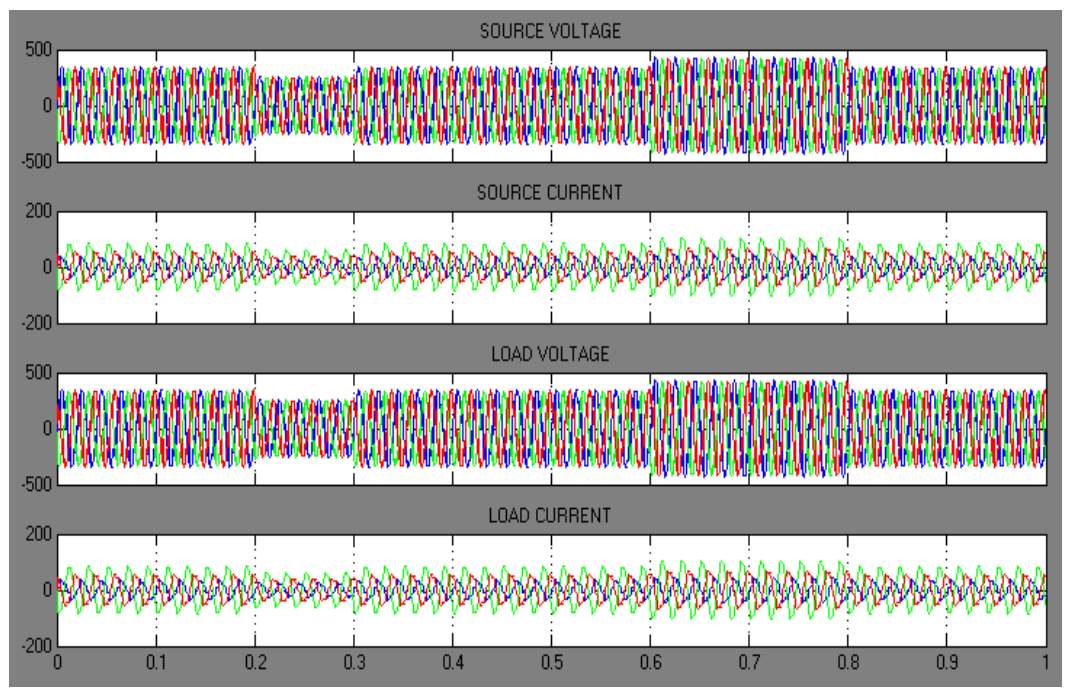

Figure 5. Source and load parameters without SAF

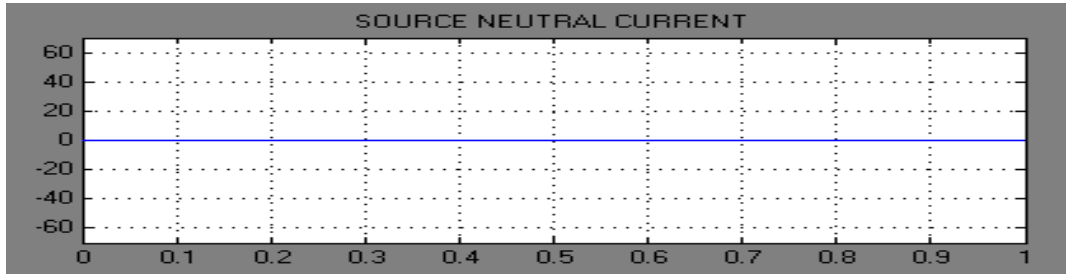

Figure 6. Source neutral current with SAF

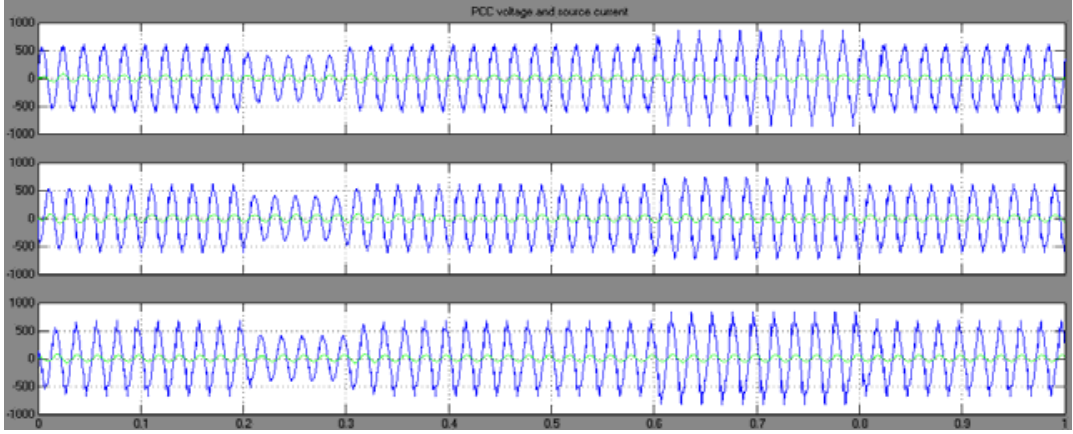

Figure 7. PCC voltage versus source current in UPF mode with one SAF

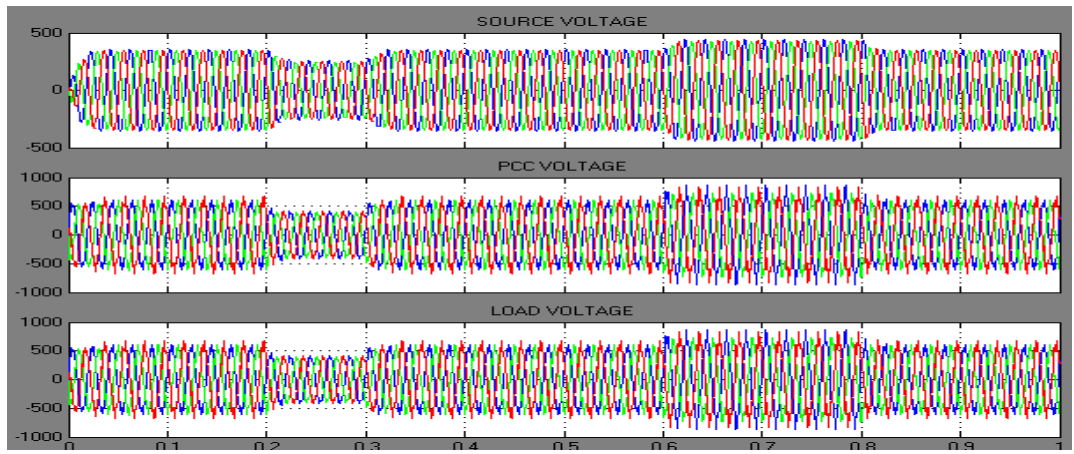

Figure 8. Source, PCC, and load voltages in UPF mode with one SAF 
Figure 9 and Figure 10 depict the waveforms when one SAF is used for compensation and is controlled by SPWM in ZVR mode of operation. Figure 9 shows the PCC voltage and source current, which are observed to be out of phase with respect to each other, since the SAF operates in ZVR mode. Therefore, it is clearly evident that UPF operation cannot be obtained when the SAF is operating in ZVR mode. Figure 10 shows the source, PCC and load voltages in ZVR mode of operation. The load voltage is found to be regulated in ZVR mode of operation even in the presence of sag and swell in source voltage.

It is clearly evident from the waveforms of Figure 7 - Figure 10 that the UPF and ZVR modes of operation cannot be achieved simultaneously by using one SAF. Hence, two SAFs are connected to the proposed system in order to obtain UPF and ZVR modes of operation, harmonic reduction and load compensation at a time.

Among the two SAFs, one operates in UPF mode and the other in ZVR mode. Figure 11 and Figure 12 depict the waveforms when two SAFs are used for compensation, and both are controlled by SPWM. Figure 11 shows the PCC voltage and source current, which are observed to be in phase with respect to each other, i.e., UPF operation, eventhough the load consists of non-linear elements. Figure 12 shows the source, PCC and load voltages when two SAFs are used. The load voltages are regulated to a constant value, i.e., ZVR mode operation even in the presence of sag and swell in the source voltage. Therefore, it can be observed that both power factor correction and voltage regulation can be attained simultaneously by using two SAFs.

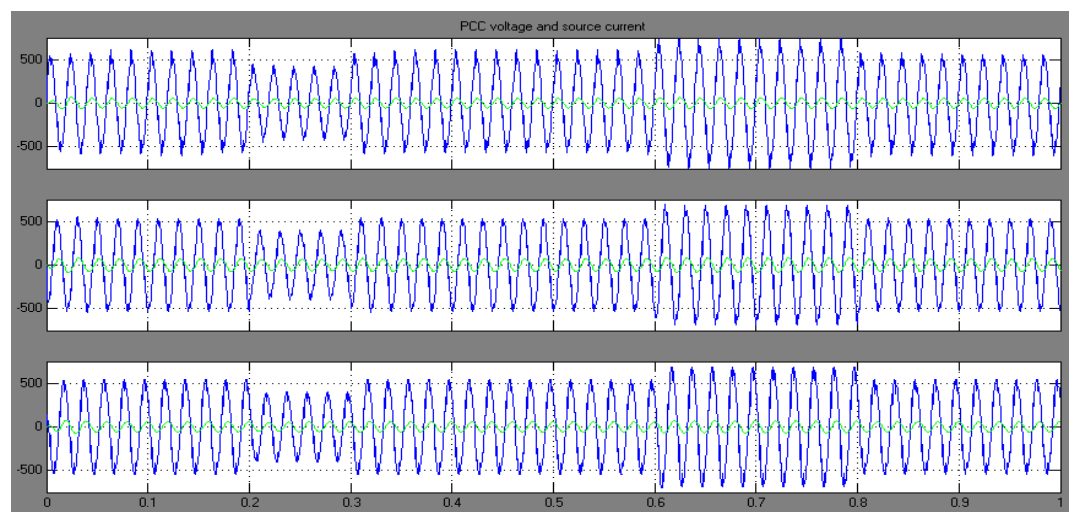

Figure 9. PCC voltage versus source current in ZVR mode with one SAF

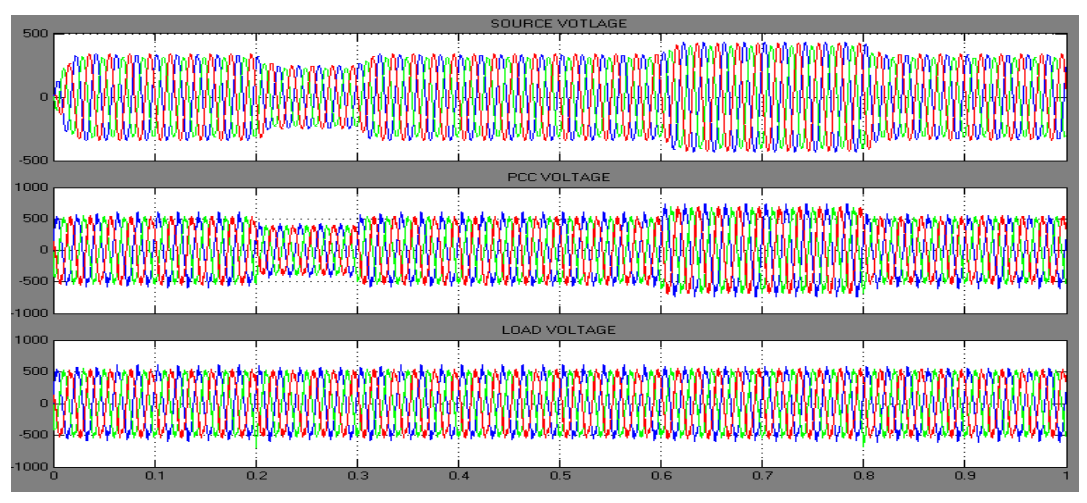

Figure 10. Source, PCC, and load voltages in ZVR mode with one SAF 


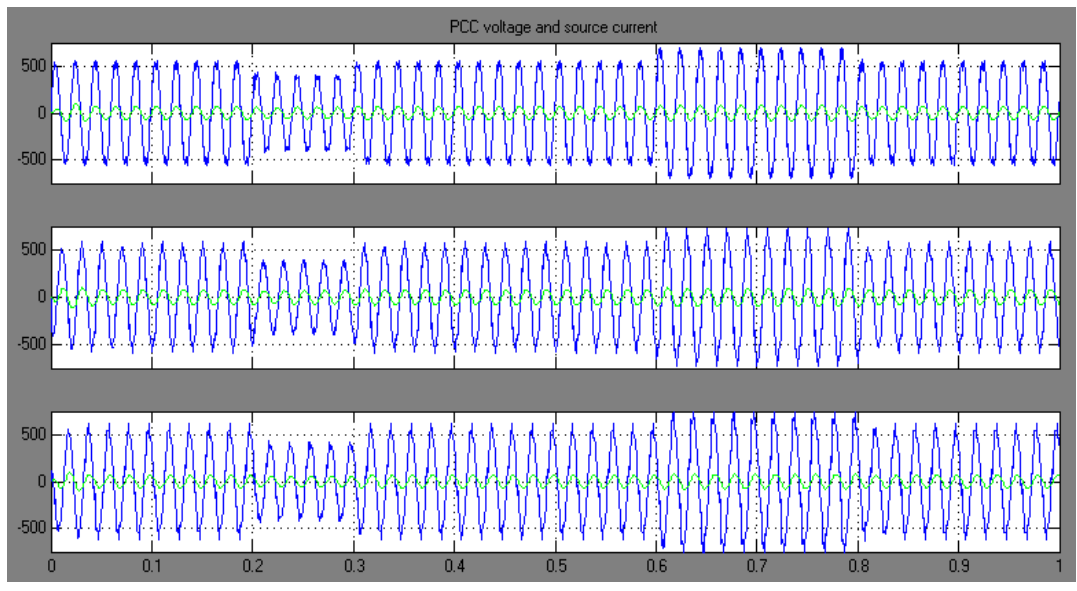

Figure 11. PCC voltage versus source current with two SAFs

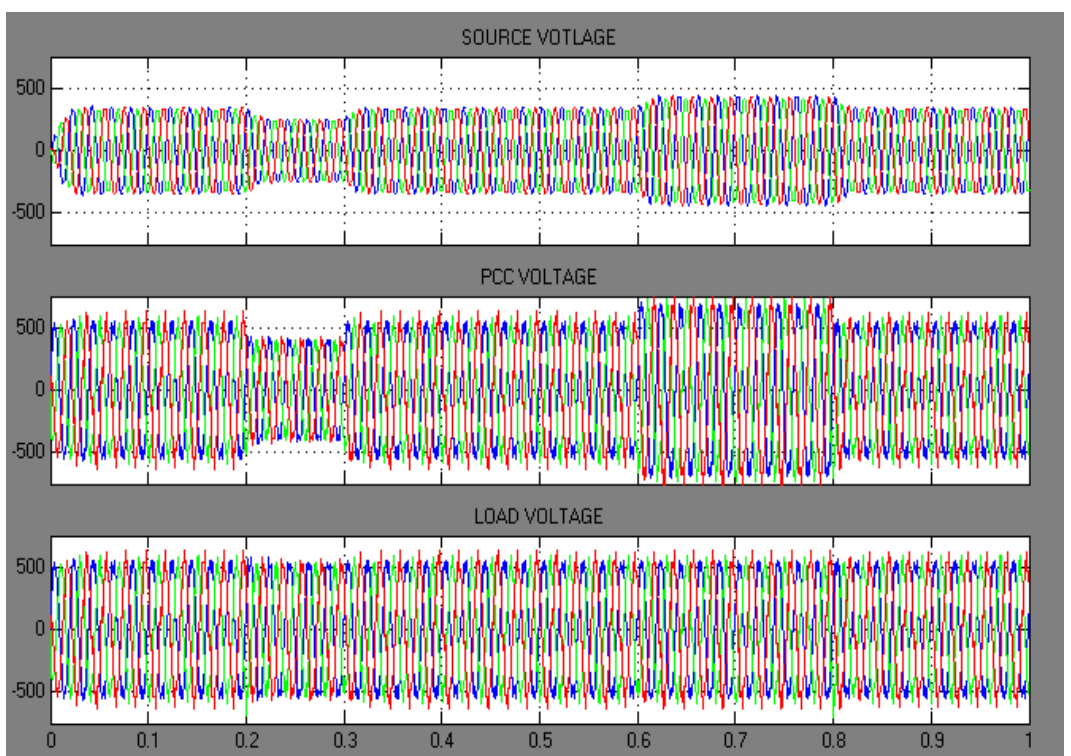

Figure 12. Source, PCC, and load voltages with two SAFs

Therefore, it can be inferred from Figures 11 and 12 that UPF and ZVR modes of operation can be obtained simultaneously when two SAFs are used. The performance of SAF is also observed by using SVM and HPWM instead of SPWM in the proposed system for all the above cases.

The THD values of phase-A source current for various firing angles and control strategies of the proposed system are listed in Table 2 . For a firing angle of $30^{\circ}, 60^{\circ}$ and $90^{\circ}$, the THD of phase-A source current is $20.66 \%, 6.94 \%$ and $5.41 \%$, respectively. It can be inferred from the tabulated values that, with SAF, the THD of phase-A source current decreased significantly, which complies with the IEEE - 519 standard. As per IEEE - 519 standard, the acceptable level of THD is less than 5\%. When one SAF has been used, the minimum values of THDs are obtained when SVM is used to generate pulses to VSC of SAF in both UPF and ZVR modes of operation. But, while using two SAFs, in which, one operates in the UPF mode controlled by SVM and the other in the ZVR mode controlled by HPWM, the lowest values of THD, i.e., $0.18 \%, 0.21 \%, 0.19 \%$ have been obtained for firing angles of $30^{\circ}, 60^{\circ}$ and $90^{\circ}$, respectively. 
Table 2. THD values for various control strategies and firing angles

\begin{tabular}{cccc}
\hline \multirow{2}{*}{ Control Strategy } & $30{ }^{\circ}$ & $60^{\circ}$ & 90 \\
\hline Without SAF & $20.66 \%$ & $6.94 \%$ & $5.41 \%$ \\
With one SAF & & \\
UPF - SPWM & $2.98 \%$ & $4.8 \%$ & $4.8 \%$ \\
ZVR - SPWM & $3.67 \%$ & $1.76 \%$ & $1.86 \%$ \\
UPF - SVM & $0.67 \%$ & $0.74 \%$ & $0.64 \%$ \\
ZVR - SVM & $0.95 \%$ & $0.74 \%$ & $0.12 \%$ \\
UPF - HPWM & $3.01 \%$ & $4.82 \%$ & $4.79 \%$ \\
ZVR - HPWM & $3.75 \%$ & $1.74 \%$ & $1.83 \%$ \\
With two SAFs & & \\
UPF \& ZVR - SPWM & $1.49 \%$ & $3.48 \%$ & $3.4 \%$ \\
UPF \& ZVR - SVM & $0.55 \%$ & $0.65 \%$ & $0.63 \%$ \\
UPF \& ZVR - HPWM & $2.9 \%$ & $4.7 \%$ & $4.73 \%$ \\
UPF- SPWM \& ZVR - SVM & $1.03 \%$ & $1.2 \%$ & $1.19 \%$ \\
UPF- SVM \& ZVR - SPWM & $0.65 \%$ & $0.65 \%$ & $0.62 \%$ \\
UPF- HPWM \& ZVR - SVM & $2.01 \%$ & $2.66 \%$ & $2.65 \%$ \\
UPF- SVM \& ZVR - HPWM & $0.18 \%$ & $0.21 \%$ & $0.19 \%$ \\
UPF - HPWM \& ZVR - SPWM & $2.89 \%$ & $4.71 \%$ & $4.72 \%$ \\
UPF - SPWM \& ZVR - HPWM & $2.89 \%$ & $4.71 \%$ & $4.72 \%$ \\
\hline
\end{tabular}

\section{CONCLUSION}

The paper has explained how two SAFs can be used to achieve the desired load compensation. The voltage and current waveforms at the source and load sides have been shown in this paper for a period of one second for a three-phase four-wire system feeding a combination of unbalanced and variable non-linear load; and the THD values have been compared for different control schemes using one SAF and two SAFs connected at PCC. It can be noted that SAF has successfully compensated all the ill-effects of the load. Further, it has been observed that UPF and ZVR modes of operation, harmonic reduction and load compensation have been attained simultaneously by using two SAFs. Likewise, it has been demonstrated that the minimum value of THD is obtained when two SAFs are used, where one is used in UPF mode controlled by SVM and the other in ZVR mode controlled by HPWM.

\section{REFERENCES}

[1] A. Priyadharshini, N. Devarajan, A.R. Uma Saranya, "Survey of Harmonics in Non-linear Loads", International Journal of Recent Technology and Engineering, vol. 1(1), pp. 92 - 97, Apr 2012.

[2] M. Jawad Ghorbani and H. Mokhtari, "Impact of Harmonics on Power Quality and Losses in Power Distribution Systems", International Journal of Electrical and Computer Engineering, vol. 5(1), pp.166 - 174, Feb 2015.

[3] A. Souli and A. Hellal, "Design of a Computer Code to Evaluate the Influence of the Harmonics in the Electrical Networks", International Journal of Electrical and Computer Engineering, vol. 2(5), pp. 681 - 690, Oct 2012.

[4] A. Chandra, Bhim Singh, B.N. Singh and K. Al-Haddad, "An Improved Control Algorithm for Voltage Regulation, Harmonic Elimination, Power-Factor Correction and Balancing of Non-Linear Loads", IEEE Transactions on Power Electronics, vol. 15(3), pp. 495-507, May 2000.

[5] H. Fujita and H. Akagi, "A Practical Approach to Harmonic Compensation in Power Systems - Series Connection of Passive and Active Filters", IEEE Transactions on Industry Applications, vol. 27(6), pp. 1020 - 1025, Nov/Dec 1991.

[6] Fang Zheng Peng, H. Akagi and A. Nabae, "A New Approach to Harmonic Compensation in Power Systems - A Combined System of Shunt Passive and Series Active Filters", IEEE Transactions on Industry Applications, vol. 26(6), pp. 983 - 990, Nov/Dec 1990.

[7] M. El-Habrouk, M.K. Darwish and P. Mehta, "Active Power Filters: A review", IEE Proceedings - Electric Power Applications, vol. 147(5), pp. 403 - 413, Sept 2000.

[8] H. Akagi, "New Trends in Active Filters for Power Conditioning", IEEE Transactions on Industry Applications, vol. 32(6), pp. 1312 - 1322, Nov/Dec 1996.

[9] Bhim Singh, K. Al-Haddad and A. Chandra, "A Review of Active Filters for Power Quality Improvement", IEEE Transactions on Industrial Electronics, vol. 46(5), pp. 960 - 971, Oct 1999.

[10] M.I.M. Montero, E.R. Cadaval and F.B. Gonzalez, "Comparison of Control Strategies for Shunt Active Power Filters in Three-Phase Four-Wire Systems", IEEE Transactions on Power Electronics, vol. 22(1), pp. 229 - 236, Jan 2007.

[11] Y. Kusuma Latha, Ch. Saibabu and Y.P. Obulesh, "Control Strategy for Three Phase Shunt Active Power Filter with Minimum Current Measurement", International Journal of Electrical and Computer Engineering, vol. 1(1), pp. $31-42$, Sept 2011.

[12] S. Sundeep and Dr. G. Madhusudhana Rao, "Modelling and Analysis of Custom Power Devices for Improve Power Quality", International Journal of Electrical and Computer Engineering, vol. 1(1), pp. 43 - 48, Sept 2011. 
[13] M. Aredes, J. Hafner and K. Heumann, “Three-Phase Four-Wire Shunt Active Filter Control Strategies”, IEEE Transactions on Power Electronics, vol. 12(2), pp. 311 - 318, Mar 1997.

[14] S. Chandrasekhar, J. Brahmmam and M. Srinu, "Mitigation of Voltage Flicker and Reduction in THD by using STATCOM", International Journal of Electrical and Computer Engineering, vol. 3(1), pp. 102 - 108, Feb 2013.

[15] A. Cavallini and G.C. Montanari, "Compensation Strategies for Shunt Active-Filter Control", IEEE Transactions on Power Electronics, vol. 9(6), pp. 587 - 593, Nov 1994.

[16] B. Singh and J. Solanki, "A Comparison of Control Algorithms for DSTATCOM", IEEE Transactions on Industrial Electronics, vol. 56(7), pp. 2738-2745, July 2009.

[17] B. Singh B, P. Jayaprakash and D.P. Kothari, "A T-connected Transformer and Three-Leg VSC Based DSTATCOM for Power Quality Improvement", IEEE Transactions on Power Electronics, vol. 23(6), pp. 2710 2718, Nov 2008.

[18] K. Ranjith Kumar and P. Sadanandam, "GA for Optimal PI in DC Voltage Regulation of DSTATCOM", International Journal of Electrical and Computer Engineering, vol. 1(2), pp. 110 - 118, Dec 2011.

[19] B. Singh, P. Jayaprakash, T.R. Somayajulu and D.P. Kothari, "Reduced Rating VSC with a Zig-Zag Transformer for Current Compensation in A Three-Phase Four-Wire Distribution System", IEEE Transactions on Power Delivery, vol. 24(1), pp. 249-259, Jan 2009.

[20] Holtz J, "Pulse Width Modulation - A Survey", IEEE Transactions on Industrial Electronics, vol. 39(5), pp. 410 420, Oct 1992.

\section{BIOGRAPHIES OF AUTHORS}
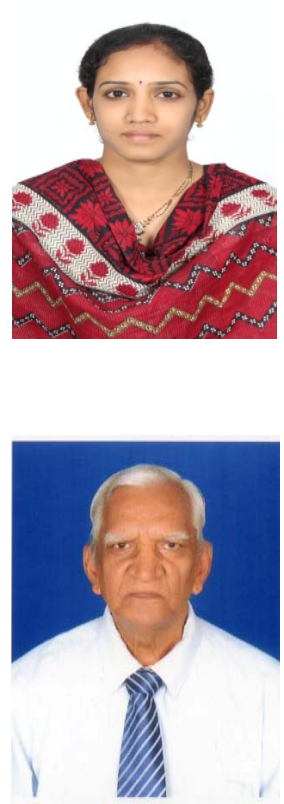

Deepthi Janyavula obtained her B.E from Andhra University in 2003, M.Tech from JNTU Hyderabad in 2009 and is currently pursuing her PhD from JNTU Hyderabad in external mode. She has about 11 years of teaching experience. For nearly 10 years, she was on the faculty of Electrical and Electronics Engineering, Padmasri Dr B V Raju Institute of Technology. Subsequently, she joined the Government of Andhra Pradesh Roads \& Buildings Department as an Assistant Executive Engineer. Currently, she is working as a Lecturer at Government Polytechnic, Sangareddy, Telangana, India. She has published six papers in various national and international journals and conferences. Her areas of interest include Power Systems, Power Quality and applications of Power Electronics to Power Systems. She is a Member of IEEE and life member of ISTE.

Satyendra Nath Saxena obtained his B E from University of Bombay, India, in 1963, M.Tech from Indian Institute of Technology (IIT) Kharagpur, India, in 1966, and Ph.D from University of Tokyo, Japan, in 1974.

He has a teaching experience of about 27 years at IIT, NIT and GRIET, He also has an experience of industrial research of about 25 years while working in Bharat Heavy Electricals Ltd (BHEL), Corporate Research \& Development (R\&D) Division, Hyderabad, India, from where he retired in 2004 as General Manager.

He has a large number of technical papers published in national and international journals and conferences. His areas of interest include electrical machines, power electronics and power systems. 